\title{
Teaching English by means of comic multimodal texts
}

\author{
Elizaveta V. Shustrova - Ekaterina I. Checkletsova - Lidija E. Volkova - \\ Tatiana V. Luzjanina
}

\section{DOI: $10.18355 /$ XL.2017.10.04.04}

\begin{abstract}
The relevance of the problem that is discussed is connected with the changing character of media and social environment. The aim of the article is to share our experience how various types of multimodal or the so called creolized texts may become a very helpful means for the study of theoretical subjects. We are mainly concerned with the blocks that traditionally form a part when teaching a modern foreign language as a would-be professional field. As a rule, these theoretical subjects are rich in linguocultural phenomena that should be shown and explained to the students. We describe how purely linguistic facts can be demonstrated and taught with the help of graphic means. Methods of investigation are formed on the basis of conceptual metaphor theory, multimodal metaphor approach. These methods of study have been further changed in the process of our own research so that the linguistic data could be analyzed in a more detailed way. In particular, much attention is given to the study of transferred meanings, pun, decomposition of set-expressions and analysis of images that are deeply rooted in culture. Stereotypes that exist in every culture, human types that become popularized; folklore and fiction characters that are projected on real people and real-life situations; linguistic means; the system of images; discourse background; translation drawbacks and their reasons - all these became part of our investigation. Multimodal texts imply the use of both verbal and visual components. Thus, different advertising techniques, cartoons (including political subjects), comic strips, posters, collage art, feature films may present the unlimited source of material. Such activities are generally offered to senior students because such work requires a high level of second language acquisition but some activities and steps can be used with less proficient learners. Basic results may be of interest to the staff and scholars dealing with linguocultural data.

Key words: graphics, creolized text, multimodal metaphor, cartoon, linguocultural data.
\end{abstract}

\section{Introduction}

Modern life is unthinkable without a vast and prominent use of the so-called creolized or multimodal texts. Y. A. Sorokin and E. F. Tarasov were the first to use the term "creolized" in reference to texts (1990). These are such textual forms that combine various semiotic systems including both verbal and visual components. The scholars (Anisimova, 2003; Bernatskaya, 2000; Voroshilova, 2007, 2013) describe two basic types of creolized texts as far as their structure is concerned: texts with partial creolization and completely creolized texts. In the first case the verbal elements are more or less autonomous with the graphic part just supporting the verbal one. Here we find scientific discourse and traditional fiction. In the second case the verbal part is blended with graphics the latter serving as an integral component. Cartoons and advertisements are the most vivid examples. The term "multimodal" has gained popularity in Europe and the USA (Forceville, Urior-Aparisi, 2009; Jewitt, 2011; Kress, 2010; Kress, Van Leeuwen, 2001; O’Halloran, 2004; Ventola et al., 2004; Zheltukhina et al., 2017).

As Ch. Forceville puts it: "If [this] tenet of conceptual metaphor theory is correct, metaphor should manifest irself not just in language but also via other modes of 
communication, such as pictures, music, sounds, and gestures. However, non-verbal and multimodal metaphor have been far less extensively studied than their verbal sisters"(Forceville, 2009, p. 19) The connection between the iconic and verbal parts is described on the levels of content proper, content and composition, content and linguistic means (Anisimova, 2003; Carroll, 1996; Marchand, 1986; Voroshilova, 2013; Shustrova, 2014a, b; Kazakov, Zakirova, Birova, 2017.).

In the process of second language acquisition multimodal/creolized texts, especially of the second type, often present a separate field of numerous mistakes and misunderstanding. At the same time they may turn into a source of fascinating material that would add vivacity into traditional classroom activities.

\section{Materials and methods}

It is true that creolized texts are easy to be found in the long history of humanity, including icons, illustrated hagiography, chronicles, etc. But it is the era of advertising and consuming together with the film industry appearance that brought creolized texts into the centre of modern civilization. That being an important part of our life makes them an easy and often entertaining source of linguocultural information ready to be used in the process of language teaching. Here we shall be concerned only with comic creolized texts although the experience and techniques we share can be easily projected upon other types of such products.

Various forms that a comic element may take in a creolized text are undoubtedly connected with the genre, textual functions, and an expected pragmatic effect. It's common knowledge that there is no universal typology of genres even in reference to the traditional textual forms. It is quite a challenge to introduce a universal typology of creolized texts that are initially a blend of various semiotic systems. In far general terms we can single out genres with the predominance of the arts component (feature films, screen versions, cartoons, clips, comic strips, collage), political, including propaganda, component (political cartoons and caricatures, collage, clips, fliers, handouts), advertising component (posters, clips, fliers, stuffers, videos), private component (blogs, graffiti, all kinds of laptop publishing and 'domestic' amateur photo and video production, scrapbooks).

For sure, each of the trends may in its turn include genre variations of its own dependent on the aim of creation, expected functions, pragmatic effect, means of circulation (TV, Internet, print, etc.), environment, and other numerous factors. At the same time one and the same text may easily combine different components of the above-mentioned types. Thus, a feature film, which initially falls under the category of arts, may show elements of bitter political or social irony and thus become blended with political and private types. In recent years much popularity has been won by feature films that together with the esthetic effect include an advertisement in disguise. That may happen when the characters shown prefer an exact brand of beverages, clothes, chocolate produced by the sponsor-company. The examples are numerous, "Devil Wears Prada" being one of them. The height of artistic and advertising effects' blending is thought to have been achieved in "Perfume: The Story of a Murderer". The appearance of the word 'advertainment' is not a coincidence as it denotes new types of creolized texts aimed at both esthetic and arts and advertising effects. Political creolized text may at the same time function both as an advertisement and as a piece of art. An advertisement in its turn is often disguised as a private 'domestic' amateur product featuring a girl, who is far from being a top-model although for sure attractive, giving very simple reasons for choosing some particular nail varnish, jeans and juice or a housewife chatting amiably to you on domestic problems, reflecting 'our feminine point of view' and offering her own experience

XLinguae, Volume 10, Issue 4, October 2017, ISSN 1337-8384, eISSN 2453-711X 
that would undoubtedly lead to presenting a product you should trust without a second thought or you would have only yourself to blame.

In the methodological aspect multimodal or creolized texts still remain a very problematic object of investigation due to the complexity of their nature. Nevertheless, being a very attractive field of investigation, multimodal texts have been studied from various angles (cf. Jewitt, 2011; Kress, 2010; McNeill, 2007; McQuarrie \& Mick, 2003; Müller, 2008; Phillips, 2003; Smith, 1996; Whittock, 1990; Wiggin \& Miller, 2003). One of our attempts to introduce and apply linguistic methods of study to this particular sphere is described in: (Shustrova, 2014a). In this article we demonstrate how linguocultural, social semantic and semasiological methods may be applied to multimodal/creolized texts' analyses in the classroom activities.

\section{Results}

Modern teaching is impossible without reference to quite a variety of creolized texts. Video, multimedia presentations and projects, interactive posters have entered our classrooms and formed a constant part of teaching. We would like to share our experience as far as creolized texts are concerned. We are basically dealing with the study of theoretical subjects that are traditionally included into curriculum when teaching a modern foreign language as a would-be professional field. As a rule, these theoretical subjects are rich in linguocultural phenomena that should be shown and explained to the students.

As an unlimited source of material we usually use advertisements of different types, caricature, cartoons, collages, posters, and video including feature films. True, it's convenient to present your theoretical issues with the help of various multimedia products, including PowerPoint. But right now we would focus upon such interactive techniques that are promoting and are based on students' high level of activity, greater degree of their involvement. Such techniques are mostly in practice in the senior years of professional university study when the would-be teachers of English are in your class. This implies that the students should have good language skills. At the same time some techniques may also be adapted when teaching English to less-proficient audience.

The subject matter for our classroom investigation includes: linguocultural stereotypes, most frequent human types, characters of folklore and literature as projected towards real people; stereotypical situations, ceremonies and rites; linguistic means; symbols; extralinguistic environment; mistakes in translation and interpreting, and the factors that cause them. The choice of activities is surely determined by the exact subject (text analysis, lexicological and semasiological aspects, cognitive linguistics, theoretical linguistic methods, etc.), the aim and particular goals of both a single lesson and a complete sequence, system of lessons. Sometimes the choice depends upon students' curiosity or a lack of cultural information needed for the better understanding of certain linguistic facts.

While we are analyzing graphics based on stereotypes, explaining such products and looking for some extra information, we recognize a "slice-of-life" and do a double take of the common things. While dealing with makeup and perfumery ads it's interesting to single out and evaluate stereotypes of beauty, prestige, success.

Stereotypical human images partially correspond to such a notion as "linguocultural type" (LT). According to Karasik (2007), "it is a prototypical personality, a representative of a certain ethno-social group that is singled out due to characteristics of verbal and non-verbal behavior, and a recognized system of values. Determination and description of such LT is one of the trends in linguocultural studies; this trend focuses upon identification of certain behavioural stereotypes that form specific 
features of a particular linguoculture. In its nature an LT is a separate type of a concept by which we understand a mental formation that includes the image, the notion and the value components". We are of the opinion that before it really turns into an LT, a certain more or less frequent or specific human type may start being reproduced in graphics. Whether it would form a long-time LT or not depends upon many factors, including illustrators' guidelines, aims and policy of advertising agencies, a wish of the audience to recognize this human type and link it to certain anticipations and satisfactions. In any case, the study of such types is necessary for a better understanding of literature, graphics, and historical background.

The "Gibson girl" would serve as an example (fig. 1). According to the dictionaries, it is "a girl typifying the fashionable ideal of the late 19th and early 20th centuries. Origin: represented in the work of Charles D. Gibson (1867-1944), American artist and illustrator" (ABBYY Lingvo, 2008). Immediately after her creation in 1890 this girl with her slender waist and luxurious hair has grown to be known as the personification of a feminine ideal. The Gibson girl blouse and the Gibson girl petticoats were all the rage.

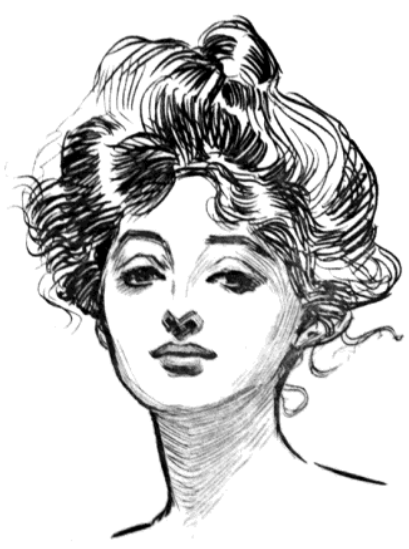

Figure 1: Gibson girl

As Charles D. Gibson put it: 'I'll tell you how I got what you have called the 'Gibson Girl.' I saw her on the streets, I saw her at the theatres, I saw her in the churches. I saw her everywhere and doing everything. I saw her idling on Fifth Avenue and at work behind the counters of the stores...[T]he nation made the type. What Zangwill calls the 'Melting Pot of Races' has resulted in a certain character; why should it not also have turned out a certain type of face?... There isn't any 'Gibson Girl,' but there are many thousands of American girls, and for that let us all thank God. ... They are beyond question the loveliest of all their sex...In the United States, of course, where natural selection has been going on, as elsewhere, and where, much more than elsewhere, that has been a great variety to choose from. The eventual American woman will be even more beautiful than the woman of to-day. Her claims to that distinction will result from a fine combination of the best points of all those many races which have helped to make our population" (Gibson Girl, 2009).

This new American beauty was exhibiting a new type of behaviour: strong, selfconfident, quite content with her situation. All this led to her changed idea of the man and his role in her life. Figures 2 and 3 emphasize the condescending behaviour of the

XLinguae, Volume 10, Issue 4, October 2017, ISSN 1337-8384, eISSN 2453-711X 
new women who amuse themselves looking through a magnifying glass at a man or indignantly and somewhat contemptuously contemplate how their partners are looking for their fans and gloves.

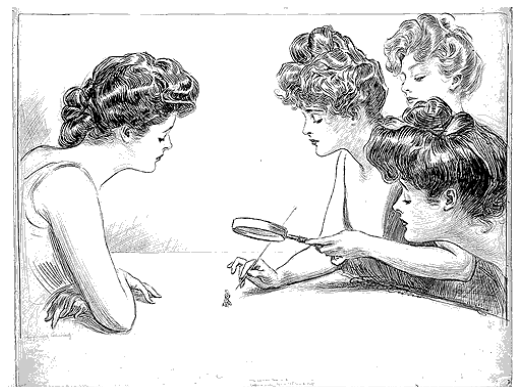

Figure 2: Gibson Girls examining a man

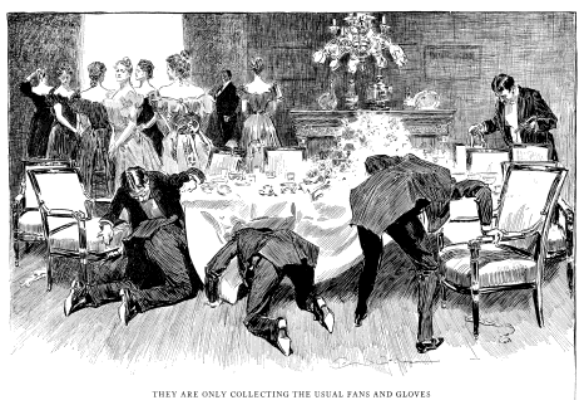

Figure 3: They are only collecting the usual fans and gloves

Charles D. Gibson would be followed by other illustrators, Harry G. Peter being one of them. It is he who would portray yet another popular new feminine type - Wonder Woman (fig. 4.). True, it was William M. Marston who identified the type. But it became possible only because such a type started appearing in American society; it was not only an allusion to mythology but a living type that hard years had brought into existence and cultivated.

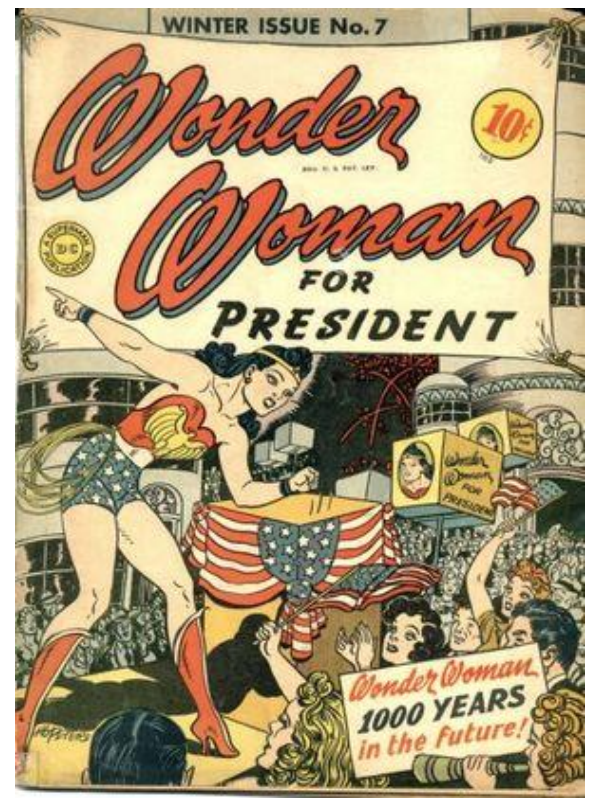

Figure 4: Wonder Woman 
Popular characters of folklore, literature, cartoons, films, etc. when being linked to certain people or situations in various types of discourse, including graphics make us be more attentive to certain works of art, help us recognize the elements that are important for a nation. Paul Conrad's creations give marvelous examples how literature, history and culture can be projected towards a politician. Figure 5. depicts Richard Nixon after the infamous Watergate Scandal, that led to his resignation, in the image of King Richard II as portrayed by William Shakespeare. The accompanying lines are: "O that I were as great as my grief, or lesser than my name. Or that I could forget what I have been. Or not remember what I must be now."

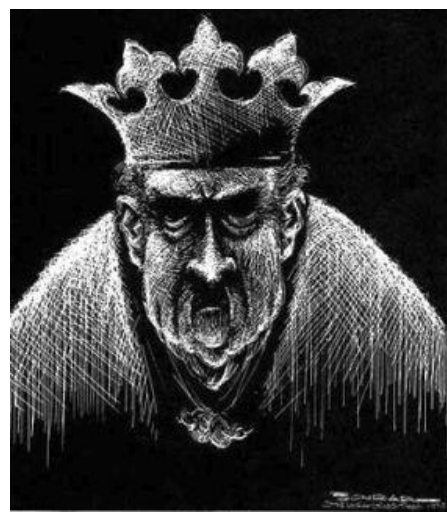

Figure 5: Nixon as King Richard II

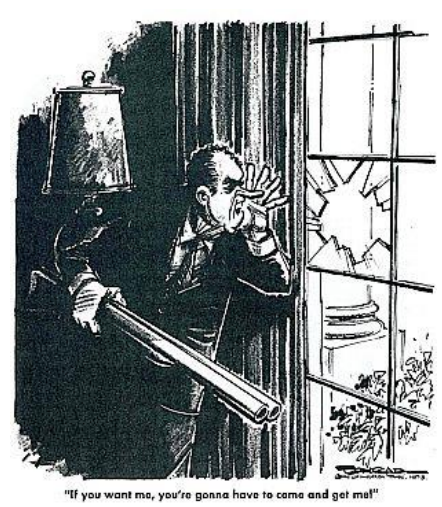

Figure 6: Nixon as a criminal

Hollywood movie scenes about criminals come into mind when we are looking at figure 6 with unfortunate President Nixon shouting: "If you want me, you're gonna have to come in and get me!" The scandalous resignation, Nixon's unwillingness to leave the White House, his desperate attempts to prove his innocence are presented as stubbornness of a criminal that has nothing to lose and thus label this behavioural type. Something of the kind we also find in Charles Adams' cartoon (Nash, Shelton, 1987). His heritage together with some creepy sense of humour can help to visualize elements of gothic style, particular vision of supernatural, the authorial image of a Victorian house (figs. 8, 9, 10), his traditional cast of characters - the "Addams Family" (figs. 10, 12), the situations that may form basis for "black" humour (fig. 11). It would help students to get a better understanding of the Gothic novel genre, to explain what stands behind such thrillers as "The Others", for example. 


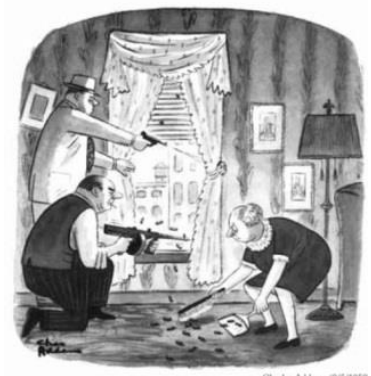

Figure 7: Charles Addams' cartoon

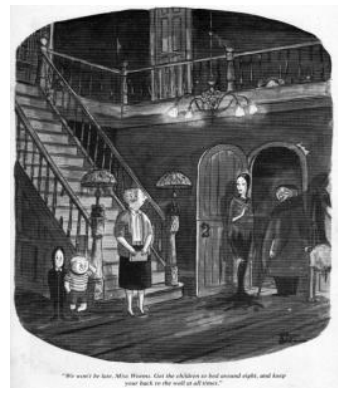

Figure 10: Addams Family

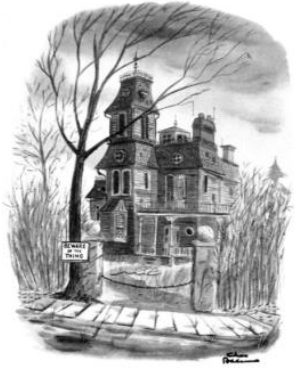

Figure 8: Victorian house

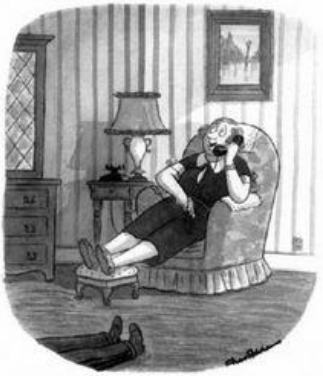

-Nothing much, Agnes. What's new with you?"

Figure 11: Addams Family

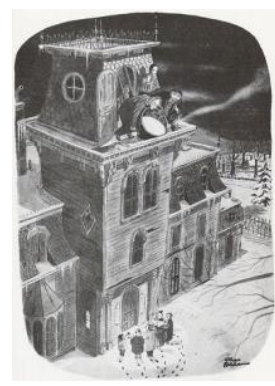

Figure 9: Victorian house

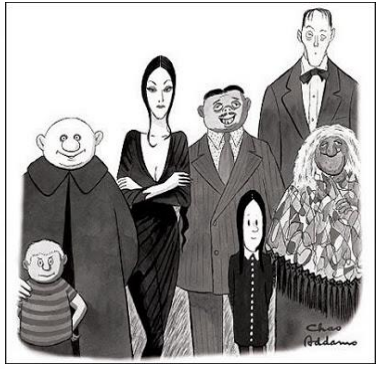

Figure 12: Addams Family

Linguistic means that form the pragmatic effect of graphics present yet another field for analytical work. It encourages students to be more attentive to the data the dictionaries provide: etymology, collocations, transferred meanings, especially in colloquial speech, slang, and idioms, frequency, etc. It is better to use explanatory dictionaries to eliminate code-switching that often interferes when bilingual dictionaries are referred to. They help students to get the pragmatic effect much quicker than English-Russian dictionaries. Having studied information about two English lexemes dove and pigeon your group would understand much better why it is dove that gives its name to chocolate and soap. Why do advertisers include the image of does and deer, ferrets in beer ads? Why do birds or sheep come together with chewing gum? Our experience proves that students are quick to respond to such activities and can hardly conceal their astonishment when they start reevaluating linguistic facts they seemed to know about. First, various types of analysis should be demonstrated, including etymological information, singling out of semantic components, explanation of collocations and their newly acquired meanings. After that the students are encouraged to find their own examples of creolized texts based on transferred meanings. Then they present their data in the group. The presentations should include the initial video or graphics coupled with different lexicographic information and the analytical part. The material is further on discussed in the group thus adding to the development of speaking skills. 
Artifacts in films which are singled out by the camera, especially in close-ups, serve as an example of a device called in fiction analysis "a metonymy blended with a symbol" (Grigoryev, Ivanova, et al., 1994). When this device is introduced in fiction, different artifacts - clothes, furniture, china, food, etc. - being part of the environment and the character - develop the symbolic line adding to the better understanding of what would happen next, how the plot would twist and work. We recommend to start with short stories that have multiple examples of artifacts that are frequent in British and American literature. As the next step, the students are offered to take a close look around, pick up some objects and try to introduce these images together with their detailed description into their own essays as if these are parts of a creative writing (stories, parts of novels). Each class starts with a brief 'symbol-quiz' when each student takes the floor and describes the chosen artifact in the context of the 'novel-tobe'. Then the group should describe their emotions, the effect produced, and give their ideas as to what the possible variations of the plot may be. When everyone has given their view, the 'author' explains his or her intentions. Thus the students become more versatile in their creative analysis, more proficient in understanding of a hidden, potential meaning of fiction, get a better ground for reading between lines having only the symbols to guide them. At the same time spontaneous speech is practiced when the students don't know what the subject for discussion may be. Unprepared oral speech is combined with tedious work and frequent references to dictionaries, on-line information when a creative part of a 'novel' is being composed. As the final step we offer a complex description of creolized texts that have "metonymies blended with symbols".

Creolized texts that exist because of an idiom at their basis may be a very productive field for lexicology and lexicography classes. We often experiment with cartoons, caricatures, advertisements, sometimes video. Thus, to understand the transferred meaning that the drawing is based upon, the student would refer to various lexicographic information, then they would find contexts, make up their own examples, change grammatical constructions, etc. All this would help to practice the idiom. Figures 13, 14, 15, 16, 17 include idioms as such: the light bulb moment, the light bulb switched on, to throw in the towel and their transformations.

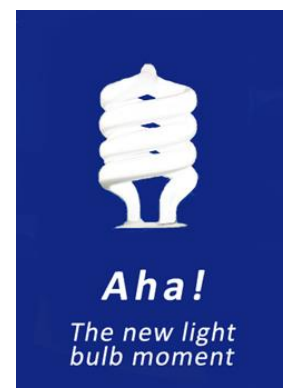

Figure 13: The new light bulb moment

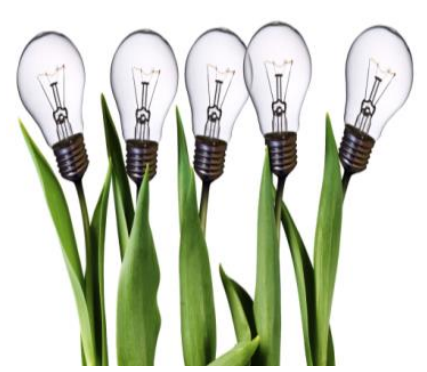

Figure 14: The rise of ideas

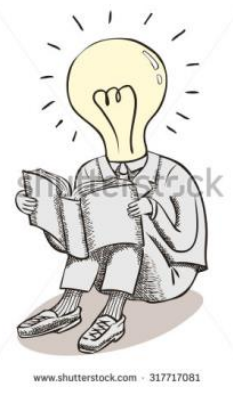

Figure 15: The bulb moment 


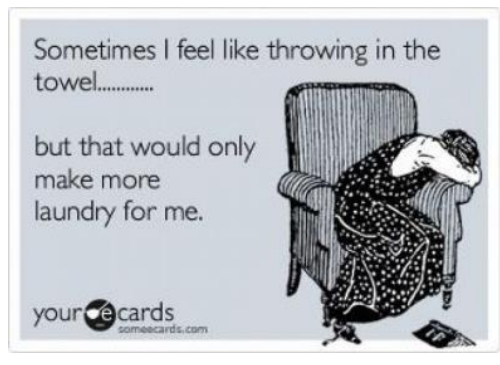

Figure 16: Making a choice

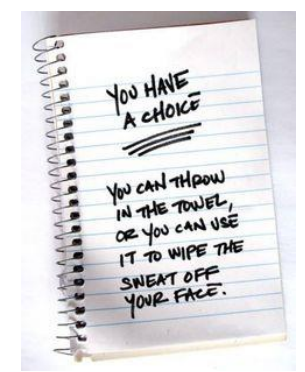

Figure 17: A piece of advice

As the final step you may offer your students to make films of their own. These may be of a different genre including thrillers, fairytales, science fiction, soap operas, romantic stories - whatever their hearts and minds are inclined to. But at the basis of the film there should be an idiom, a set-expression or a number of these. It is very important that you should limit the choice to the units you have been training together. It will help to prevent possible mistakes in understanding and usage which are practically unavoidable if the students choose idioms on their own. To make the matter still worse, in this latter case the mistakes will be well-trained during rehearsals and shooting. As our results show, when you introduce various activities based on the same units for quite a time, you'll get excellent creative products with no mistakes as far as the idioms are concerned. You won't need more than 10-15 minutes but if you constantly refer to the same units introducing them in speech, phonetic exercises, warming-up activities, while discussing some other topics, the students will grow confident about the material. Thus, you will improve speaking skills and widen the outlook. One more important tip - the students should take their time while making the video. It may take them up to three months and you'd better not hurry them up.

Extralinguistic information presents another fascinating aspect. It may be connected with the collection of fashions and trends that used to be full vogue at the times described in the story or novel under analysis. It would make students refer to quite a variety of sources including dictionaries. If you take food for analysis it may be interesting to compare gastometaphors that exist in different languages and cultural associations.

\section{Discussions}

As we have already said, there is no universal typology; the principles are dependent upon the particular sphere and scholarly trend. We would also like to share our point of view as far as the nature of multimodal/creolized texts and their possible bases for classification are concerned.

In many cases distinctive features of creolized text, including the comic side, are determined by the consumer environment, the audience it is created for. Here we may find various age, gender, social and professional groups. It is often some hobby or some particular common sphere of interests that form ground for the unifying. Internet activities are a ready source of examples. It is there we may easily find and surf the ocean of groups, communities that share not only the interests but also a sense of humor and their vision of irony that become reflected in graphics. What may seem funny for a particular community can lose its effect and even turn into an enigma for many others. Some elements of creolized text found on amateur dressmakers' sites serve as a good example. One of the visitors has uploaded a photo of a 'Chanel' jacket of her own making with her own comments. It immediately generates a heated jocular 
debate accompanied with new photos and sketches uploading. The reason for fun would be lost upon those who don't share sewing interests. But if this polylogue is treated as a complete text (which is possible as the common topic functions as a textforming element) and presented to another professional community, they would find an entirely different reason for fun bordering on ridicule. Professional tailors and couturiers would marvel at the stitches zig-zagging unevenly, at the cheap cloth chosen, at the band being scorched. Had Karl Lagerfeld seen the 'creation', he would've thought "Oh, Gosh! Is that the Thing?!" The terms are not used in a correct way either or ignored altogether. Professional linguists would mark the unusual spelling and 'new' grammar rules. It is worth mentioning that some professionals try to show way for improvement both in sewing and editing on the same site but the reason of their fun is a deep mystery for the 'authors' of the text.

If we have a closer look at neologisms connected with creolized texts, we'll find not only traditional groups of recipients (such as age groups, kiddie-tainment being an example) but some new consumer environments and words denoting them (eg. eatertainment). That brings the idea of the potential consumer environment being a convenient criterion for creolized texts classifications.

Yet another criterion may be provided by the theme and general mood. Thus, such a trend as retro-tainment appeared which is known for its appeal to visual clichés of the 'good old days', romanticized images of the past. It is a frequent thing in advertising. Scrapbooking is unthinkable without the atmosphere of the past. In cases as these it is the theme that sets the rules for the tone, including irony and satire.

The aim and pragmatic effect are surely the key elements for the majority of rationally created texts including creolized ones. If we pay attention to more recent varieties, such a trend as irritainment may be considered, it being annoying, embarrassing, upsetting and fascinating at one and the same time. Killographic production is yet another example when the prior aim is to cause violence, to provoke and feed it. Such examples are aplenty on the sites of radical nationalists and terrorists. Here belong ISIS and Taliban dreadful videos. The rules of humor grossly deviate from generally accepted idea of a good joke.

It is worth mentioning that many types of creolized texts that have special English lexemes denoting them still bear no names in Russian. Even already existing English terms are not borrowed although these types are well known to the Russian public. It introduces yet another criterion that sets the margins for the comic - linguocultural, or in narrower terms national, determination of creolized text. Professional interpreters are well aware of the difficulties that arise when an advertisement is being translated or, better to say, transplanted into another culture not only language. In many cases things that haven't been intended to be funny in the donor-culture would miraculously turn into something not proper and ridiculous in the recipient-culture. Words denoting one and the same object may get clashing potential semes in different languages. For example, one and the same animal, plant, food may have entirely different associations, hence, the differences in the transferred meanings including metaphor. Word-building models also interfere. It especially concerns conversion so typical for English and not frequent in Russian. The multiple meanings of one and the same English word that can fulfill two or even three grammatical functions cease to exist for Russian environment. Vice versa, Russian inflections that give triple twists of meaning can hardly be rendered into English by one concise phrase that advertising requires. Precedent phenomena of various types (eg. names of celebrities, quotations, popular texts, including books, song lyrics, films, documents) and historic context are among other those elements that obscure the funny, ironic or sarcastic side.

Next side of the comic element in creolized text appears when the combination of the verbal and visual components creates an unusual, unplanned effect the advertising

XLinguae, Volume 10, Issue 4, October 2017, ISSN 1337-8384, eISSN 2453-711X 
agency couldn't have foreseen. Specialists in advertising will be quick to recollect cases when the initial image was designed as a reference to the realm of beauty and has turned into something incongruous instead. Such unplanned crudities are sure to be found in traditional textual forms but a pictorial element when combined with a text would give a far wider scope to imagination.

More than that, an accidental inappropriate combination of the verbal and visual components may start functioning as a new textual integrity and would appear in Internet as a comic product. Take for example two ad leaflets one depicting a steaming dish of meat dumplings while the other is proudly showing a toilet bowl. The leaflets are designed in practically the same colours and placed side by side. The advertising agency never planned such an effect, but one cannot help taking the two unfortunate ads as one visual and semantic field. We are of the opinion that one of distinctive features that make a creolized text different from traditional textual varieties is its capacity to make various mental or conceptual spaces blend at a greater speed thus creating new grounds for singling out the comic or ironic side.

According to Y. Lintzbach, one of the basic distinctions between verbal and visual texts and mental operations involved in their interpretation is determined by the texts' reference to the temporal characteristics: "the fundamental difference between a verbal text and a drawing is that a drawing refers to one moment while a text involves a number of such moments. That's why a drawing correlates with a text as some unit correlates with a set of such units" (Lintzbach, 1916, p. 200-201). It is less obvious in reference to complex large-scale creolized texts, screen versions for example, but for a vast majority of other creolized types it's true.

Last but not least, the comic element of a creolized text may be determined by it being static or dynamic. The rules for the funny effect creation would differ if we are looking at a caricature or a collage not based on the transition of elements and if we are watching a video. The possibility to accompany the elements with the sound would also play an important part. When the sound-track follows the visual part phonetic elements are likely to be used, out of homonyms the homophones would be preferred while static comic texts are exemplified with homographs. For sure, the general sound environment would also influence the audience.

All these factors cannot but influence the type of the text and methods you choose for classroom activities.

\section{Conclusion}

To sum it up, we would emphasize once again the importance of multimodal texts' introduction into professional portfolios at different levels of the second language acquisition. Yet another aspect that has formed the object of the discussion given above is concerned with the choice of purely linguistic methods that may give good result in scientific analysis of multimodal texts. We have shared our experience in both linguistic ways of analysis and classroom activities.

\section{Recommendations}

The results of our research are of interest to the English language teachers and students of pedagogical faculties. The results may be applied to various age groups but due to the complexity of the object it would be advisable to use these activities with learners that demonstrate good language skills. Some results are intended for scholars whose field of professional interest is built around linguocultural data, social semiotics and cognitive linguistics. 


\section{Bibliograpic references}

ABBYY Lingvo: software programme. 2008. Issue 14.0.0.715. ABBYY Software Ltd.

ANISIMOVA, E.E. 2003, Text linguistics and cross-cultural communication. Moscow. Academia. 128 p.

BEMATSKAYA, A. A. 2000. About the problem of text "creolization": history and modern aspects. In: Speech Communication, vol. 3, n. 11, pp. 104-110. ISSN: 01676393.

CARROL, N. 1996. A note on film metaphor. In Theorizing the Moving Image. Cambridge. Cambridge University Press. 452 p. ISBN: 978-0521466073.

CARTOONS BY CH. ADAMS. Available online: http//www.theinvisibleagent.wordpress.com.

DOYLE, J. 2011. Enemy of the President, 1970s. Available online: PopHistoryDig.com. jdoyle@pophistorydig.com

FORCEVILLE, Ch, - URIOR-APARISI, E. 2009. Multimodal Metaphor. Berlin. Mouton De Gruyter. 470 p.

GIBSON GIRL. 2009. In Kate Chopin - The 1900's answer to Barbie. Available online: http//www.loyno.edu/ kchopin/new/women/images/gibson.

GRIGORYEV, V. P. - IVANOVA, N. N. - NEKRASOVA, E. A. SEVERSKAYA, O. I. 1994. Sketches about the history of the language in Russian poetry of XX. Moscow. Nauka. $272 \mathrm{p}$.

HANESOVA, D. 2015. Plurilingual and intercultural awareness of future teachers. In: New Educational Review, vol. 42. N. 4. pp. 79-90. ISSN 1732-6729.

HANESOVA, D. - NELSON, A. - BADLEY, K. 2017. Educators in search of the fine line between use and misuse of new technologies. In: Communications Scientific letters of the University of Zilina. Vol. 19. N. 1. pp. 44-48. ISSN 13354205.

JEWITT, C. 2011. The Routledge Handbook of Multimodal Analysis. New York. Routledge. ISBN: 978-0415667777.

KARASIK, V. I. 2007. Linguistic keys. Volgograd. Paradigma. 520 p.

KAZAKOV, A. V. - ZAKIROVA, V. G. - BIROVA, J. 2017. Modeling the Process of Forming Social and Cultural Competence among Students of Linguistics Faculty. In: Man In India, vol. 97, n. 14, pp. 291-305. ISSN: 00251569.

KRALOVA, Z. - METRUK, R. 2010. Television Programmes in the Acquisition of English Pronunciation. In: Komunikacie, vol. 12, n. 3, pp. 35-39. ISSN 1335-4205.

KRESS, G. - VAN LEEUWEN, Th. 2001. Multimodal Discourse: The Modes and Media of Contemporary Communication. London. Arnold. $152 \mathrm{p}$.

KRESS, G. 2010. Multimodality: a Social Semiotic Approach. New York. Routledge. $232 \mathrm{p}$.

LINTZBACH, Y. 1916. Principles of Philosophic Language. Study of exact linguistics. Saint Petersburg. Peter. 421 p.

MARCHAND, R. 1986. Advertising the American Dream. New York. University of California Press. 448 p.

McNEILL, D. 2007. Gesture and Thought. Chicago. Chicago University Press. 328 p. McQUARRIE, E. - MICK, D. 2003. The contribution of semiotic and rhetorical perspectives to the explanation of visual persuasion in advertising. In L. M. Scott \& R. Batra (Eds.), Persuasive Imaginary: A Consumer Response Perspective. Mahwah. Lawrence Erlbaum. pp. 284-291.

MULLER, C. 2008. Metaphors Dead and Alive, Sleeping and Walking: a Dynamic View. Chicago. Chicago University Press. 290 p.

NASH, G. B. - SHELTON, C. J. 1987. The Private Side of American History. Reading in Everyday Life: 2 v. New York. Harcourt Brace Jovanovich Publishers.

XLinguae, Volume 10, Issue 4, October 2017, ISSN 1337-8384, eISSN 2453-711X 
$459 \mathrm{p}$.

O'HALlORAN, K. 2004. Multimodal Discourse Analysis. London. Continuum. $256 \mathrm{p}$.

PHILLIPS, B. 2003. Understanding visual metaphor. In L. M. Scott \& R. Batra (Eds.), Persuasive Imaginary: A Consumer Response Perspective. Mahwah. Lawrence Erlbaum. pp. 297-310.

PINTEREST. In Pinterest: The World's Catalog of Ideas. Available online: http://www.pinterest.com/.

SMITH, K. 1996. Laughing at the way we see: The role of visual organizing principles in cartoon humor. In: International Journal of Humor Research, vol. 9, pp. 19-38. ISSN: 1613-3722.

SOMEECARDS. Available online: http://www. someecards.com/.

SOROKIN, Y.A. - TARASOV, E.F. 1990. Creolized Texts and their Communicative Function. Speech Influence Enhancement. Moscow. Nauka. 240 p.

SHUSTROVA, E.V. 2014a. Barack Obama and Modern American Cartoon. Ekaterinbug. USPU. 370 p.

SHUSTROVA, E.V. 2014b. Methods Applied for Analysis of Graphic Metaphor. In: Pedagogical Education in Russia, vol. 6, pp. 70-80. ISSN: 2079-8717.

VENTOLA, E. - CASSILLY, Ch. - KALTENBACHER, M. 2004. Perspectives on Multimodality. Amsterdam. Philadelphia. Benjamins. 249 p.

VOROSHILOVA, M. B. 2007. Creolized Text: Aspects of Study. In: Political Linguistics, vol. 21, pp. 75-80. ISBN 9789027226716.

VOROSHILOVA, M. B. 2013. Political Creolized Text: Keys to Understanding. Ekaterinbug. USPU. 194 p.

WHITTOCK, T. 1990. Metaphor and Film. Cambridge. Cambridge University Press. $188 \mathrm{p}$.

WIGGIN, A. - MILLER, Ch. 2003. "Uncle Sam wants you!” Exploring verbal-visual juxtapositions in television advertising. In L. M. Scott \& R. Batra (Eds.), Persuasive Imaginary: A Consumer Response Perspective. Mahwah. Lawrence Erlbaum. pp. 267-221.

ZHELTUKHINA, M. R. - VIKULOVA, L. G. - MIKHAYLOVA, S. V. BORBOTKO, L. A. - MASALIMOVA, A. R. 2017. Communicative theatre space in the linguistic and pragmatic paradigm. XLinguae, vol. 10, n. 2, pp. 85-100. ISSN 1337-8384.

Words: 5803

Characters: 37322 (20,7 standard pages)

Doctor of Philology Elizaveta V. Shustrova

Professor of the Department of German Philology

of the Institute of Psychology and Education in

Russian State Vocational Pedagogical University,

11 Mashinostroiteley street

620012 Ekaterinburg

Russia

elizaveta.schustrova@yandex.ru

Ekaterina I. Checkletsova

Department of German Philology

of the Institute of Psychology and Education in

Russian State Vocational Pedagogical University,

11 Mashinostroiteley street 
620012 Ekaterinburg

Russia

Che_106@mail.ru

Lidija E. Volkova

Department of German Philology

of the Institute of Psychology and Education in

Russian State Vocational Pedagogical University,

11 Mashinostroiteley street

620012 Ekaterinburg

Russia

bella.uskova@rsvpu.ru

Tatiana V. Luzjanina

Department of German Philology

of the Institute of Psychology and Education

in Russian State Vocational Pedagogical University,

11 Mashinostroiteley street

620012 Ekaterinburg

Russia

bella.uskova@rsvpu.ru

XLinguae, Volume 10, Issue 4, October 2017, ISSN 1337-8384, eISSN 2453-711X 